\title{
Tendências e alterações climáticas no Estado de Sergipe, nordeste do Brasil
}

\author{
Climatic trends and changes in the State of Sergipe, northeast Brazil
}

\author{
Francisco Jablinski Castelhano ${ }^{1 *} \bowtie\left(\mathbb{D}\right.$, Josefa Eliane Santana de Siqueira Pinto ${ }^{2} \bowtie(\mathbb{C}$ \\ 1Departamento de Geografia, Universidade Federal do Rio Grande do Norte, \\ Natal, Rio Grande do Norte, Brasil \\ 2Departamento de Geografia, Universidade Federal de Sergipe, São Cristovão, \\ Sergipe, Brasil \\ E-mail: josefaeliane@ufs.br \\ *E-mail para correspondência: francisco.castelhano@ufrn.br
}

Recebido (Received): 10/05/2021 Aceito (Accepted): 17/11/2021

Resumo: Entendendo a complexidade da atmosfera, em seus componentes sistêmicos, internos e externos e o seu envolver para com a Terra, faz crescer a necessidade de seu conhecimento, em escalas que venham integrar para contribuir em análises geográficas. Partindo deste pressuposto, o objetivo deste artigo é pensar sob uma perspectiva socioambiental, a variabilidade climática no Estado do Sergipe, nordeste do Brasil, com análises das tendências futuras para índices climáticos. Tal avaliação realizou-se a partir de uma análise estatística com base nos vinte e sete índices de mudanças climáticas propostos por Peterson et al., (2001) e recomendados pela Organização Mundial Meteorológica. Os índices utilizam-se de dados climáticos em escala diária, sendo conhecidos como "Índices ETCCDI". Foi analisada a tendência dos índices previamente gerados através do método de Mann Kendall. Constatou-se tendências a queda nos valores anuais de chuva em todo o estado. Em relação às variáveis térmicas, observou-se uma ampla tendência, ao longo de todo estado, para aumento nos extremos tanto nas temperaturas máximas quanto mínimas. Perdura no estado uma problemática socioambiental regional.

Palavras-chave: Temperatura; Precipitação; Indices extremos; Análise geográfica; Dinâmica socioambiental.

Abstract: Understanding the complexity of the atmosphere, in its systemic, internal, and external components involving the Earth, make the growth for its knowledge a necessity, at any scale, that may contribute to the geographical analysis. Based on that, the aim o this research is to understand, from a socio-environmental perspective, the climatic variability in the State of Sergipe, northeastern Brazil, with analyzes of future trends for climate indexes. To assess the state's climatic variability, a statistical analysis was performed based on the twenty-seven climate change indices proposed by Peterson et al., (2001) and recommended by the World Meteorological Organization. The indices use climatic data on a daily scale, and are known as "ETCCDI Indices". A trend analysis of previously generated indexes was done using the Mann Kendall method. Negative trends were found for rainfall values across the state. In terms of thermal variables, a wide increase trend was observed, throughout the state, for extremes in both maximum and minimum temperatures. The regional socio-environmental problem persists in the state.

Keywords: Temperature; Precipitation; Extreme indices; Geographical analysis; Socioenvironmental dynamics

\section{Introdução}

Compreendido como o grande paradigma da ciência climática contemporânea, as mudanças climáticas tornaram-se presentes nos últimos anos em diversos espectros da ciência, seja ela ambiental, política e até social. Ilustrado por inúmeras produções culturais, a mudança no clima global habita o imaginário popular e se situa como um dos maiores temores coletivos, embora a ciência ainda tenha um longo caminho a ser percorrido no que tange a sua compreensão. 
Liderando a discussão cientifica a respeito das mudanças climáticas o Painel Intergovernamental de Mudanças Climáticas (Intergovernmental Panel on Climate Change - IPCC) surge como principal órgão de pesquisa em nível mundial, agregando cientistas e pesquisas de múltiplas áreas do conhecimento e de países de todo o globo.

Esta instituição surge em 1988 como órgão oficial da ONU para assuntos relativos aos impactos da atividade humana no clima e desde então, vem publicando suas prospecções embasadas por modelos estatísticos de cenários possíveis para o clima a nível mundial na forma de relatórios.

Os modelos e seus resultados, amplamente discutidos e criticados, surgem como principal embasamento para políticas públicas e pesquisas no âmbito das mudanças climáticas.

O relatório publicado em 2014 chamado AR5 aponta primeiramente um aumento médio global de $0,9^{\circ} \mathrm{C}$ comparando o ano de 1850 a 2005 e aponta um possível crescimento que varia de $0,3{ }^{\circ} \mathrm{C}$ a $4,8{ }^{\circ} \mathrm{C}$ até 2100 em relação a temperatura global média do período 1985-2005 (IPCC, 2014). O relatório por si só não se aprofunda especificamente na questão brasileira, cabendo aos órgãos locais a tarefa de agregar estudos específicos e aprofundar a escala dos modelos globais do IPCC a realidade brasileira, realizando o chamado downscaling.

Neste sentido, em 2009, é criado o Painel Brasileiro de Mudanças Climáticas, órgão que segue os parâmetros do IPCC, congregando mais de trezentos pesquisadores brasileiros e estrangeiros, de múltiplas áreas e realizando relatórios específicos para os cenários brasileiros (MARENGO, 2014).

O PBMC publicou seu primeiro relatório em 2014, embasando-se nos modelos utilizados pelo IPCC em seu quarto relatório publicado em 2007 e, portanto, com certa defasagem. O relatório traz um capitulo para cenários específicos de cada região brasileira.

Por mais precisos que sejam tais cenários, o próprio órgão alerta para a necessidade de estudos em escala local, de modo a detalhar e localizar os conhecimentos a respeito das prováveis e eminentes mudanças no clima, respeitando especificidades regionais.

As dimensões continentais do país, aliada a grande diferença nos níveis de vulnerabilidade social entre os estados brasileiros torna necessário que estudos específicos para cada região sejam perpetuados, de modo a se aproximar da realidade vivida em cada ponto, analisado com rigor acadêmico.

A partir destas reflexões, o presente artigo tem como objetivo analisar a variabilidade e tendências futuras para índices climáticos no estado do Sergipe, nordeste do Brasil, e promover uma análise geográfica crítica da situação do estado a partir de uma perspectiva socioambiental.

Alguns estudos envolvendo alterações climáticas na região nordeste do Brasil apontam possíveis cenários e modificações ocorridas nos últimos anos. Realizando pesquisa sem utilizar modelos e projeções futuras, Dubreuil et al., (2018) analisaram o clima do Brasil sob a ótica da Classificação de Koppen. Os pesquisadores levantaram dados de 208 estações meteorológicas do país e as dividiram entre o período 19641989 e 1990-2015, analisando em cada estação meteorológica os tipos de clima anuais seguindo a classificação clássica proposta por Koppen mais frequentes, e como os mesmos se alteraram de um período a outro.

Sintetizando as alterações encontradas na pesquisa de Dubreuil et al., (2018) percebe-se, no território de Sergipe, alterações para climas mais secos tanto no litoral quanto no sertão, sendo esta uma tendência para a região nordeste.

Pinto (1999) considera que um pequeno território não desmerece sua validade universal, impondo-se um conjunto de propriedades geográficas, tais como: Dimensão, hierarquia, fluxo, homogeneidade, analogia, classificação e interação. E ainda considera a variabilidade como termo sobre o qual recai maior imprecisão.

Para a realização deste estudo, foram utilizados dados climáticos de sete estações meteorológicas, das quais seis se localizam no estado sergipano e uma no estado vizinho de Alagoas, próxima a divisa estadual.

A partir dos dados, foram calculados índices climáticos específicos que denotassem a situação de extremos térmicos e pluviométricos para o território sergipano. A análise de tendências históricas permitiu conhecimento e reflexões da condição e evolução destes índices, bem como o subsidio para a discussão geográfica a respeito dos cenários de alterações climáticos que se desenham para Sergipe, e suas repercussões.

Esta metodologia pode ser observada em estudos realizados para a região nordeste (COSTA et al., 2020a); no estado de Minas Gerais (NATIVIDADE et al., 2017) e interior da Paraíba (COSTA et al., 2020b), todavia, um estudo especifico para o Sergipe até o momento não foi realizado. 
Convém salientar outras pesquisas do clima no estado sergipano por Pinto (1985, 1999 e 2015), fundadas no elemento pluviométrico, em bases temporais diversas, mas no mesmo espaço, tendo como perspectiva de análise a questão do semiárido.

O princípio norteador foi o analítico descritivo, envolvendo tempo cronológico e espaço. Esta é outra proposta, abrangendo os índices climáticos, sintética e dinâmica, mais atual, com novas tecnologias de representação, com resultados visuais e reflexivos e considerando a vulnerabilidade social da região.

\section{Materiais e métodos}

O estado de Sergipe localiza-se na região do Nordeste do Brasil, sendo fronteiriço ao estado de Alagoas ao norte e Bahia ao sul. O estado é o menor do Brasil com aproximadamente $21910 \mathrm{~km}^{2}$ divididos em 75 municípios.

Dentre os 75 municípios do estado, 29 encontram-se dentro da área denominada semiárido brasileiro ou polígono das secas. Os municípios assim designados têm registros anuais de chuvas abaixo de $800 \mathrm{~mm}$, índice de aridez calculado em até 0,5 e risco de seca superior a 60\% (SUDENE, 2018).

Nesta área, vivem ao todo 478.935 habitantes, ou um total de $21 \%$ da população do estado, que segundo estimativas de 2018 eram de 2.278.308 habitantes (IBGE, 2020).

O estado apresenta altos índices de vulnerabilidade social, com um total de 63,3\% de sua população tendo rendimentos mensais de até um salário mínimo e 48,9\% não chegando a completar o ensino fundamental (IBGE, 2010).

Não para menos, está entre os últimos estados brasileiros em níveis de PIB per capita, com valor correspondente a aproximadamente metade do PIB per capita em nível nacional (IBGE, 2019). Os resultados recentes da Pesquisa Nacional por Amostra de Domicílios (IBGE, 2019), apontam ainda o estado como o mais desigual das unidades federativas do país com o maior índice de Gini dentre os estados $(0,58)$. Segundo dita pesquisa, $10 \%$ da população sergipana concentra $47,3 \%$ do rendimento do estado.

Apesar de a maior parte de seu PIB ser gerada pelo setor de serviços e de indústrias, dados do último censo agropecuário (IBGE, 2017), apontam que o estado sergipano destina cerca de $14.608,6 \mathrm{~km}^{2}$ para produção agrícola, ou cerca de $66 \%$ de seu território, onde trabalham cerca de $10,14 \%$ de sua população. Apesar disto, cerca de $48 \%$ do PIB estadual concentra-se na capital, Aracaju, localizada no litoral do território, sendo esta também a cidade com maior índice de desenvolvimento humano do estado com 0,770, próximo ao de países como Sérvia ou Cuba. A região do semiárido por outro lado, abriga os municípios com menores índices, com destaque para Poço Redondo com um índice de 0,529 e Riachão do Dantas com 0,539, ambas semelhantes a países como Paquistão ou Tanzânia (IBGE,2010).

No estado de Sergipe se configura os divisores naturais da escala regional: Sertão, Agreste e Zona da Mata, cujos significados etimológicos reproduzem interior, transição e litoral, entre o agreste e a praia respectivamente.

Em termos climáticos, é possível dividir o estado de outra maneira, em duas grandes porções. A primeira denominada Zona da Mata, percorrendo uma faixa por todo o litoral do estado, onde temos o predomínio do clima do tipo As, portanto caracterizado como tropical com verões secos, temperaturas médias superiores a $18^{\circ} \mathrm{C}$ e precipitações anuais superiores a $800 \mathrm{~mm}$. Em direção ao interior do estado, temos a área de clima semiárido do tipo BSh, com chuvas entre 200 e $750 \mathrm{~mm}$ anuais concentradas em poucos períodos do ano (meses de maio a julho), pouca nebulosidade, altos níveis de radiação solar e baixa umidade relativa do ar (PINTO, 1985).

Para a concepção deste estudo, foram utilizados dados coletados por sete estações meteorológicas apresentadas pela Figura 1, as quais duas situam-se na zona da mata (Aracaju e Brejo Grande), uma na zona de transição (Itabaianinha) e as demais quatro (Poço Verde, Carira, Pão de Açúcar e Propriá) na região do semiárido. A estação Pão de Açúcar encontra-se no estado de Alagoas, mas pela proximidade, na divisa estadual com o Sergipe foi incluída neste estudo.

A Tabela 1 apresenta as características de cada estação meteorológica utilizada neste estudo. O estado do Sergipe apresenta um total de nove estações meteorológicas, todavia três delas foram instaladas em 2017, apresentando, portanto, uma série de dados muito curta. Assim sendo, foram filtradas as estações com séries de dados inferiores a dez anos, totalizando seis estações do estado sergipano e uma de Alagoas. Os dados foram coletados até o final do ano de 2019 e as falhas nas séries foram desconsideradas. 

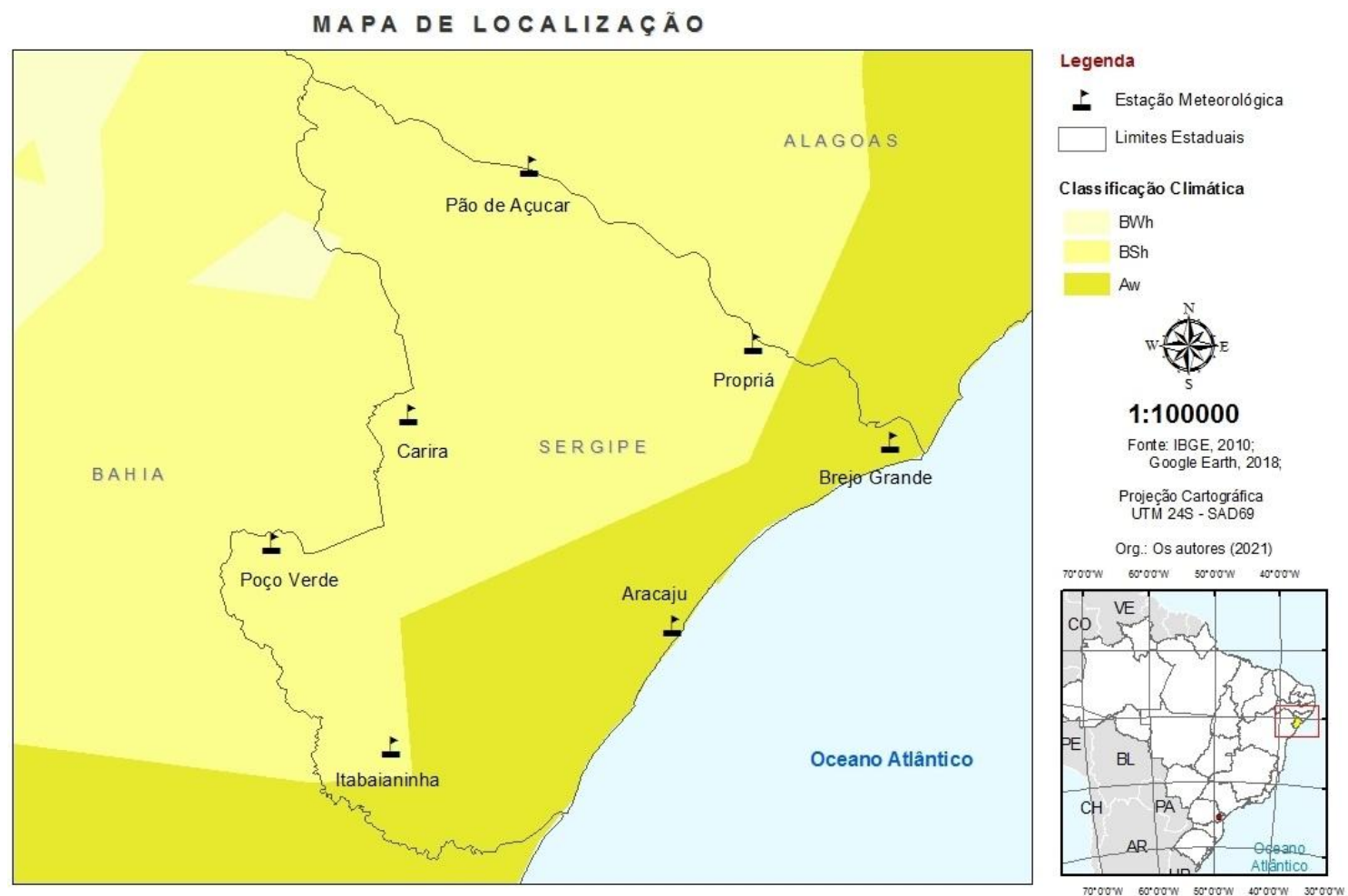

Figura 1: Localização das Estações Meteorológicas utilizadas. Fonte: IBGE e INMET, 2019. Org.: Autores.

As séries utilizadas apresentam diferentes tamanhos, com três estações apresentando doze anos de dados, uma com quarenta e sete, duas com cinquenta e sete e uma estação com cinquenta e nove anos de dados. Sabe-se que o ideal seria trabalhar com janelas de dados próximas, todavia, tal fato resultaria ou em uma significativa redução da amostra espacial ou da amostra temporal de dados disponíveis. A utilização de dados com diferentes séries temporais para análises de tendências pode ser visto em Sanches et al. (2017), Penereiro, Martins e Beretta (2016) e Oliveira, Mello e Marques (2020). Ressalta-se que tal fato foi levado em conta nas análises posteriores.

Tabela 1: Características das Estações Meteorológicas utilizadas

\begin{tabular}{lccccc}
\hline NOME & LATITUDE & LONGITUDE & ALTITUDE (m) & TIPO & INICIO DA SÉRIE \\
\hline Itabaianinha & $-11,27$ & $-37,75$ & 205 & Convencional & 1963 \\
Poço Verde & $-10,73$ & $-38,10$ & 367 & Automática & 2008 \\
Carira & $-10,39$ & $-37,74$ & 290 & Automática & 2008 \\
Aracaju & $-10,95$ & $-37,05$ & 4 & Convencional & 1961 \\
Pão de Açúcar & $-9,74$ & $-36,82$ & 21 & Convencional & 1973 \\
Própria & $-10,21$ & $-36,84$ & 18 & Convencional & 1963 \\
Brejo Grande & $-10,47$ & $-36,48$ & 6 & Automática & 2008 \\
\hline
\end{tabular}

Fonte: INMET (2020). Org.: Autores.

Para avaliar as alterações climáticas do estado de Sergipe, buscou-se realizar uma análise estatística com base nos vinte e sete índices de mudanças climáticas propostos por Peterson et al., (2001) e recomendados pela Organização Mundial Meteorológica. Os índices utilizam-se de dados em escala diária de temperatura máxima, temperatura mínima e precipitação, sendo conhecidos como "Índices ETCCDI".

Estes índices foram criados com o objetivo de facilitar a análise de alterações climáticas extremas a partir de dados em escala diária, suas análises em conjunto a testes estatísticos de tendência revelariam possíveis alterações ou variâncias nos climas em escala local, representando uma guideline utilizada mundialmente para análises de variabilidade climática regional (SOUZA et al. 2020).

Em estudo realizado por Araujo e Brito (2011), alguns dos índices supracitados foram calculados a partir de dados coletados em estações do Sergipe e da Bahia entre os anos de 1947 e 1991. A análise em questão limitou-se a atuar sobre os dados referentes a chuva, e demonstrou tendências a queda nos dias consecutivos com chuva, bem como um aumento no período seco. 
Além disso, os autores sugerem fortes relações entres estes índices e a incidência de eventos como El Nino Oscilação Sul (ENSO) e com a Temperatura de Superfície do Mar (TSM) (SST) do Atlântico e Pacífico.

Visando analisar de forma mais ampla as alterações climáticas no estado do Sergipe, optou-se por calcular um total de nove índices, envolvendo as variáveis de precipitação e temperatura. Os índices e suas características estão descritas na Tabela 2.

Tabela 2: Índices de Variabilidade Climática Utilizados

\begin{tabular}{|c|c|c|}
\hline Índice & Sigla & Características \\
\hline Valores Máximos de Temperatura Máxima & TXX & Valor máximo de temperatura máxima diária por mês \\
\hline Valores Máximos de Temperatura Mínima & TNX & Valor máximo de temperatura mínima diária por mês \\
\hline Valores Mínimos de Temperatura Máxima & TXN & Valor mínimo de temperatura Máxima diária por mês \\
\hline Valores Mínimos de Temperatura Mínima & TNN & Valor mínimo de temperatura mínima diária por mês \\
\hline $\begin{array}{l}\text { Indíce Simplificado de Intensidade de } \\
\text { Chuva }\end{array}$ & SDII & $\begin{array}{l}\text { Soma das precipitações em dias com chuva dividido } \\
\text { pelo número de dias com chuva no ano }\end{array}$ \\
\hline Precipitação Total & PRCPTOT & Total Anual de Precipitação \\
\hline Dias Secos Contínuos & CDD & $\begin{array}{l}\text { Contagem anual do maior número de dias seguidos em } \\
\text { que a prec. }<1 \mathrm{~mm}\end{array}$ \\
\hline Dias úmidos Contínuos & CWD & $\begin{array}{l}\text { Contagem anual do maior número de dias seguidos em } \\
\text { que a prec. }>1 \mathrm{~mm}\end{array}$ \\
\hline Chuva Diária Máxima Mensal & RX1DAY & Valor máximo de chuva diária por mês \\
\hline
\end{tabular}

FONTE: Peterson et.al (2001) Org.: Autores

A análise de tendência dos índices previamente gerados se deu através do cálculo de tendências de Mann Kendall (MANN, 1945, KENDALL, 1975). Tal técnica aponta a existência ou não de uma tendência monotônica ao crescimento ou a queda nos valores analisados.

O Teste de Mann Kendall se encaixa como um teste estatístico não paramétrico, portanto, ideal para analisar tendências de séries históricas consideradas sem distribuições normais e sem a necessidade de independência entre os dados amostrais, tornando-o um dos testes de tendência mais utilizado nas análises de series históricas de dados climáticos (PINHEIRO, 2016; MOREIRA; NAGHETTINI, 2016), assim como, também amplamente utilizado em conjunto ao cálculo dos indícies climáticos supracitados (RAZAVI et al., 2016; KEGGENHOFF et al., 2014).

A aplicação do teste de Mann Kendall se sucedeu através do pacote Kendall para R, e gera como resultados os valores $p$-value e tau que apontam a presença ou não de tendências monotônicas e o seu sentido (positivo ou negativo) respectivamente.

Considerou-se no presente estudo, o nível de significância superior a 90\% como indicativo ou não a presença de tendências monotônicas, propondo escala por força da significância em $90 \%, 95 \%$ e $99 \%$ para as tendências seguindo metodologia proposta por Pinheiro (2016). Assim, se considera como indicador de tendência os valores de $p$-value inferiores a 0,1 . Já o valor de tau, se positivo, indica uma tendência ao crescimento, e quando negativo, aponta uma tendência ao decréscimo.

Os resultados dos testes de tendência foram na sequência localizados junto ao território sergipano, com auxílio de técnicas de cartografia temática junto ao software ArcGis 9.3. Optou-se pela utilização de símbolos distintos para representar cartograficamente os índices cujas tendencias foram positivas, negativas ou não significantes, e a diferenciação por tons apresentou a significância das tendências encontradas. Tal mapeamento permitiu uma análise geográfica das tendências climáticas para o estado do Sergipe.

\section{Resultados}

Os resultados dos índices referentes as variáveis térmicas revelam cenários de maneira geral, de aquecimento para todo o estado.

A Figura 2 apresenta os resultados para o índice TXX. Observa-se que apenas as estações nos municípios de Carira e Brejo Grande não apresentaram tendência significativa, o que pode ser fruto da menor série temporal analisada em relação às demais estações.

Dito índice analisa os valores máximos de temperatura máxima, e aponta tendências ao crescimento com 99\% de significância para as estações em Propriá, Aracaju e Itabaianinha. A estação Pão de Açúcar registrou 
tendência ao crescimento com significância de $95 \%$ e a estação de Poço Verde, outra com serie temporal menor, registrou significância de $90 \%$ em sua tendência positiva.

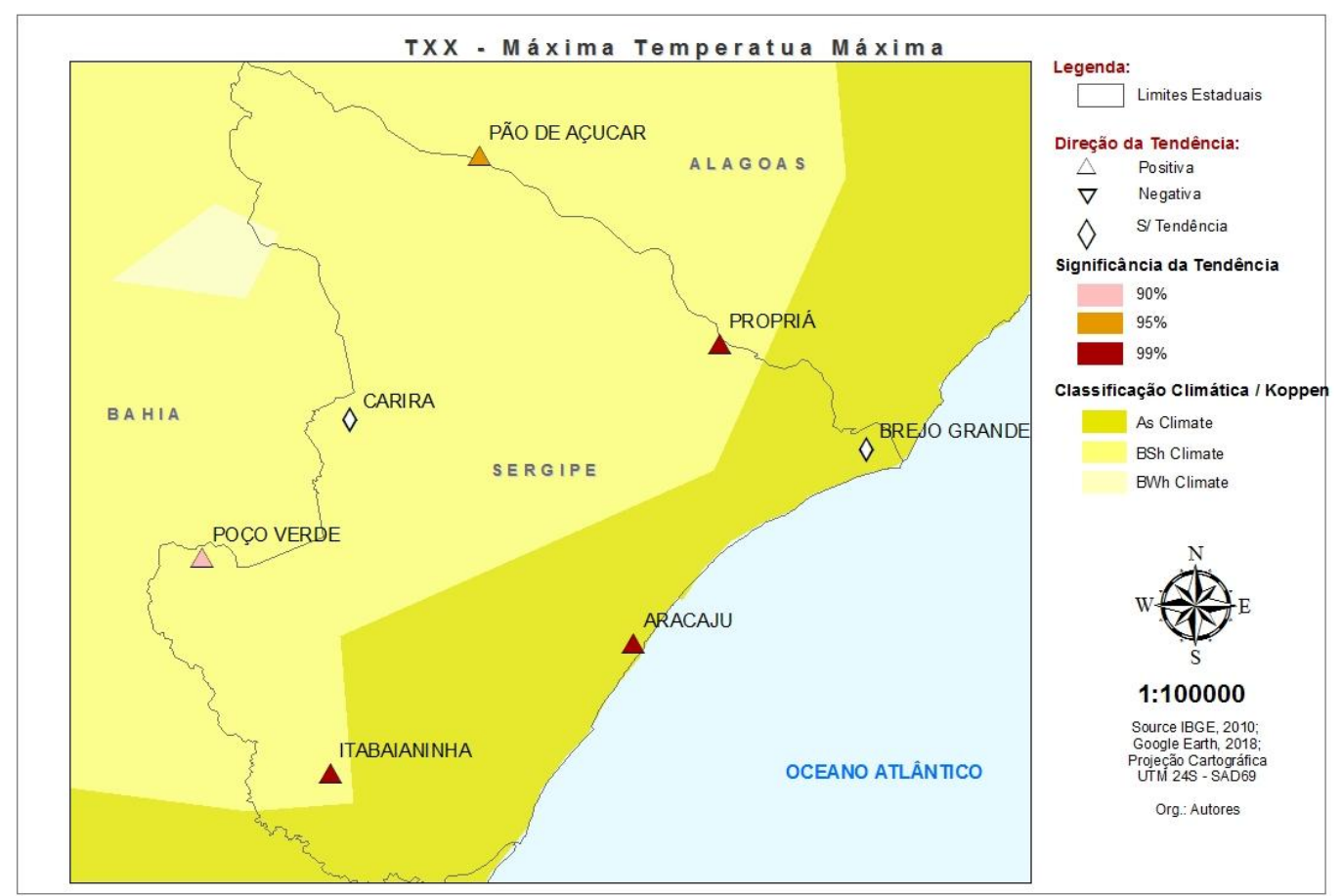

Figura 2: Tendências para o índice TXX. Fonte: IBGE e INMET, 2019. Org.: Autores

A temperatura mínima também tem apresentado lógica espacial semelhante. A Figura 3 revela os valores de tendência para o índice TNX, que representa os maiores valores de temperatura mínima das séries temporais.

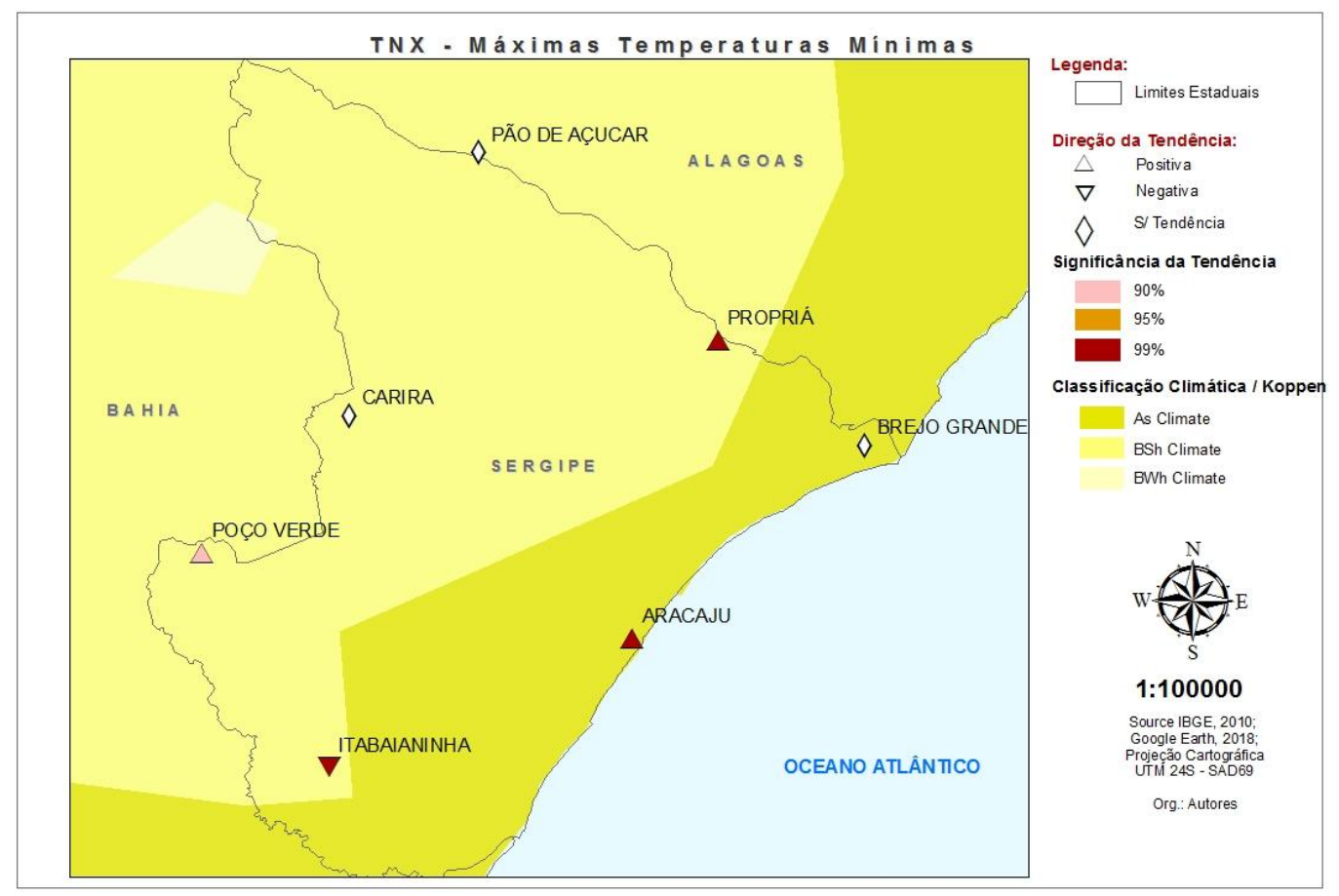

Figura 3: Tendências para o índice TNX. Fonte: IBGE e INMET, 2019. Org.: Autores

Observa-se novamente as cidades de Brejo Grande e Carira com ausência de tendências, juntamente, a cidade de Pão de Açúcar, na divisa com Alagoas, que, para este índice também não apresentou tendências. 
As cidades de Aracaju e Propriá apresentaram forte tendência com significância de $99 \%$ ao crescimento dos valores máximos de sua temperatura mínima, enquanto que Poço Verde apresentou igual tendência, mas com significância de $95 \%$.

Chama à atenção a cidade de Itabaianinha que demonstra tendências a diminuição de seus maiores valores de temperatura mínima, com significância de $99 \%$ a esta tendência.

Analisando as tendências para os índices referentes a temperaturas mínimas das séries, observamos novamente, tendência positiva com 99\% de significância nas cidades de Aracaju, Propriá e Itabaianinha, tendência positiva com 95\% nas cidades de Pão de Açúcar e ausência de tendência para as demais (Figura 4).

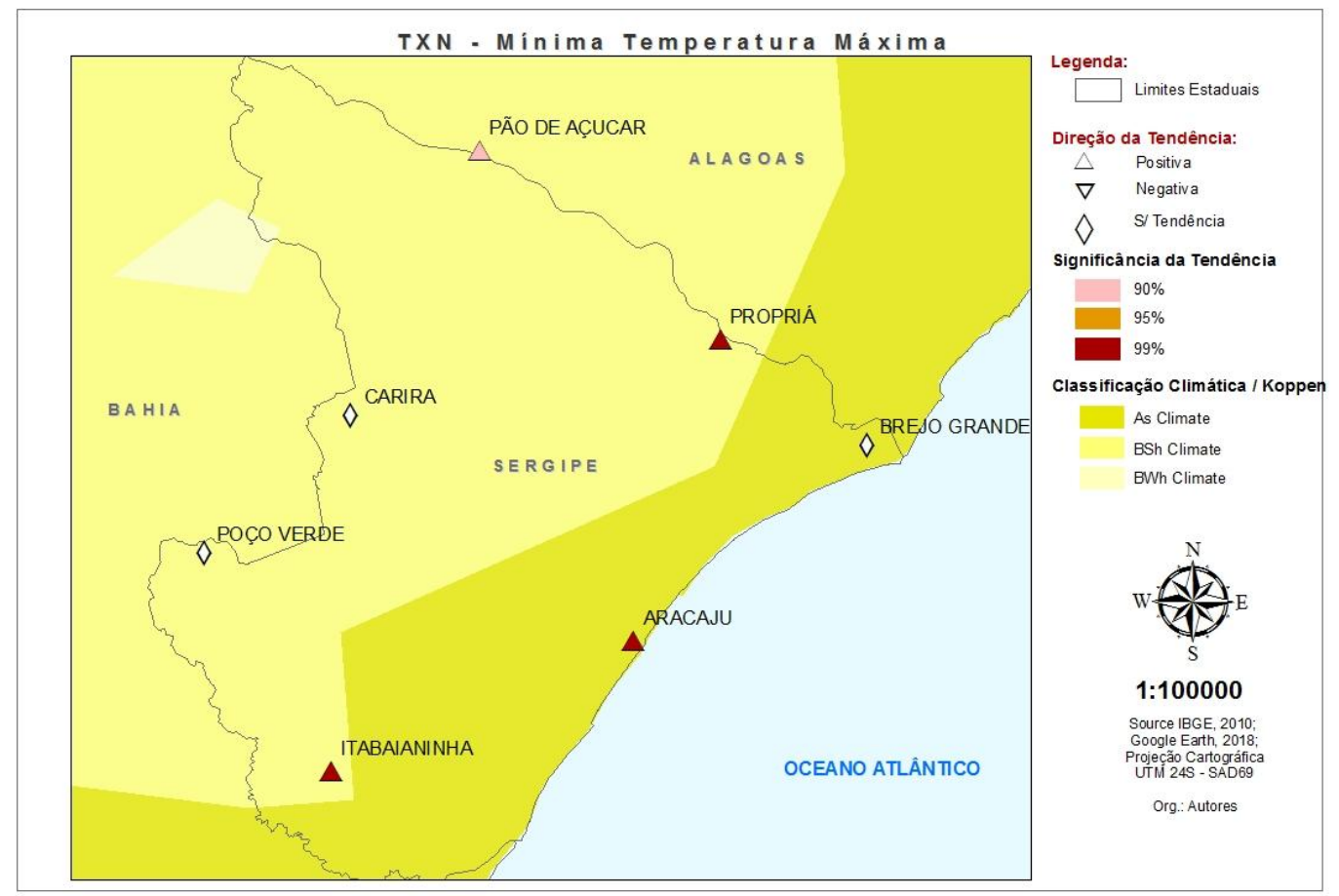

Figura 4: Tendências para o índice TXN. Fonte: IBGE e INMET, 2019. Org.: Autores

O ultimo índice cujas análises se embasam em valores de temperatura, o índice TNN, que analisa os menores valores das temperaturas mínimas, tem suas tendências reveladas pela Figura 5.

As tendências para o calculo deste índice foram os que revelaram o maior número de estações com tendências positivas a 99\% de significância, totalizando-se em quatro, sendo elas Pão de Açúcar, Propriá, Aracaju e Itabaianinha.

Por outro lado, as estações Poço Verde, Carira e Brejo Grande, revelaram novamente, ausência de tendências significativas.

Reitera-se que estas estações foram instaladas em 2008, com séries temporais relativamente inferiores aos demais pontos de coleta. Todavia, tais informações sugerem que, ao menos durante seu período de atividade, não puderam ser constatadas alterações significativas em seus dados. Todavia, tal fato pode indicar que a instalação de tal estação já pode ter ocorrido dentro de uma conjuntura de mudanças no clima indicada pelas demais séries, o que justificaria a ausência de uma tendência significativa nestes locais.

Após os índices de caráter térmico, passa-se a análise das tendências de índices ligados aos registros de precipitação, totalizando cinco índices. A Figura 6 espacializa as tendências e suas significâncias para o índice PRCPTOT, que indica o total anual de precipitação das estações. 


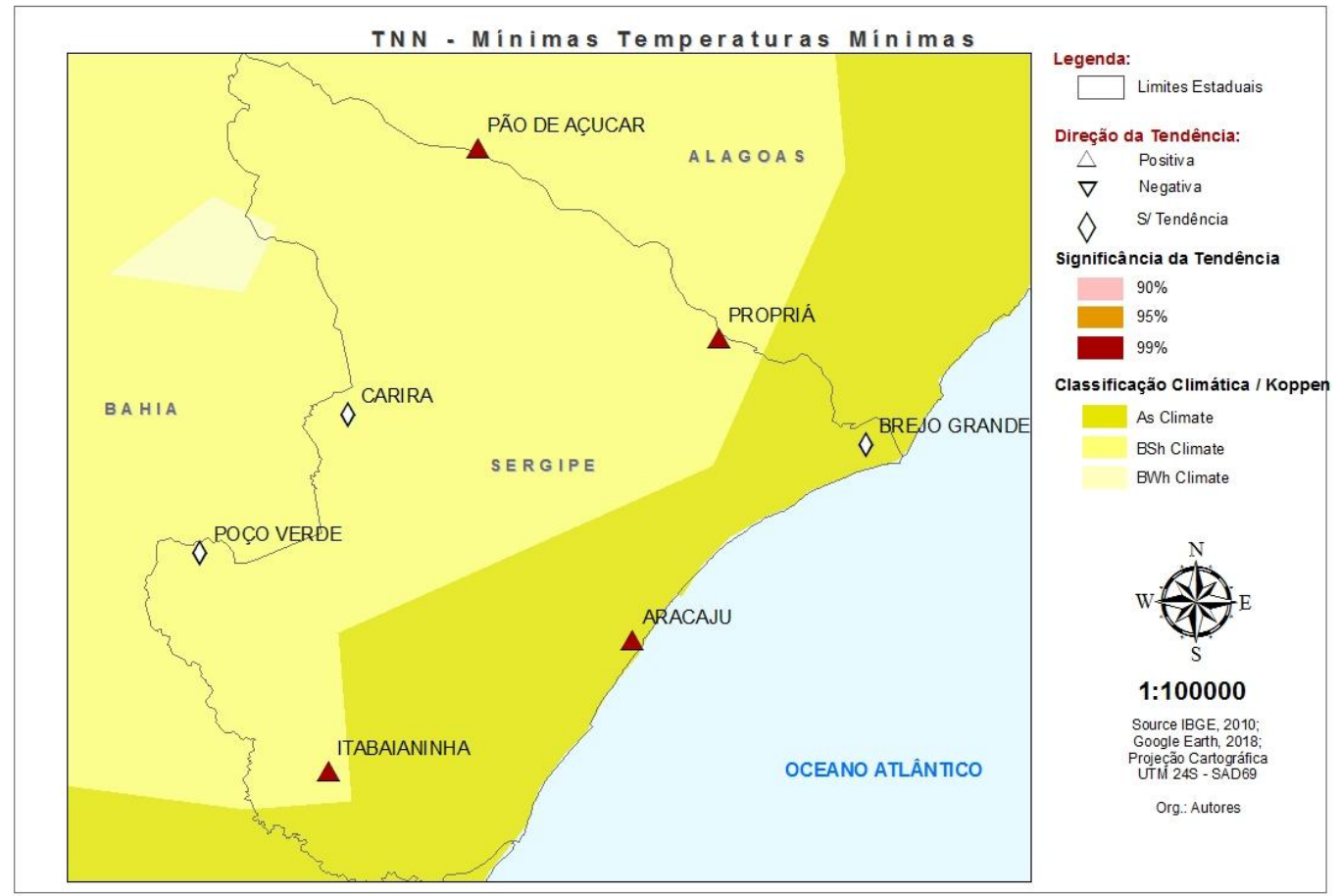

Figura 5: Tendências para o índice TNN. Fonte: IBGE e INMET, 2019. Org.: Autores

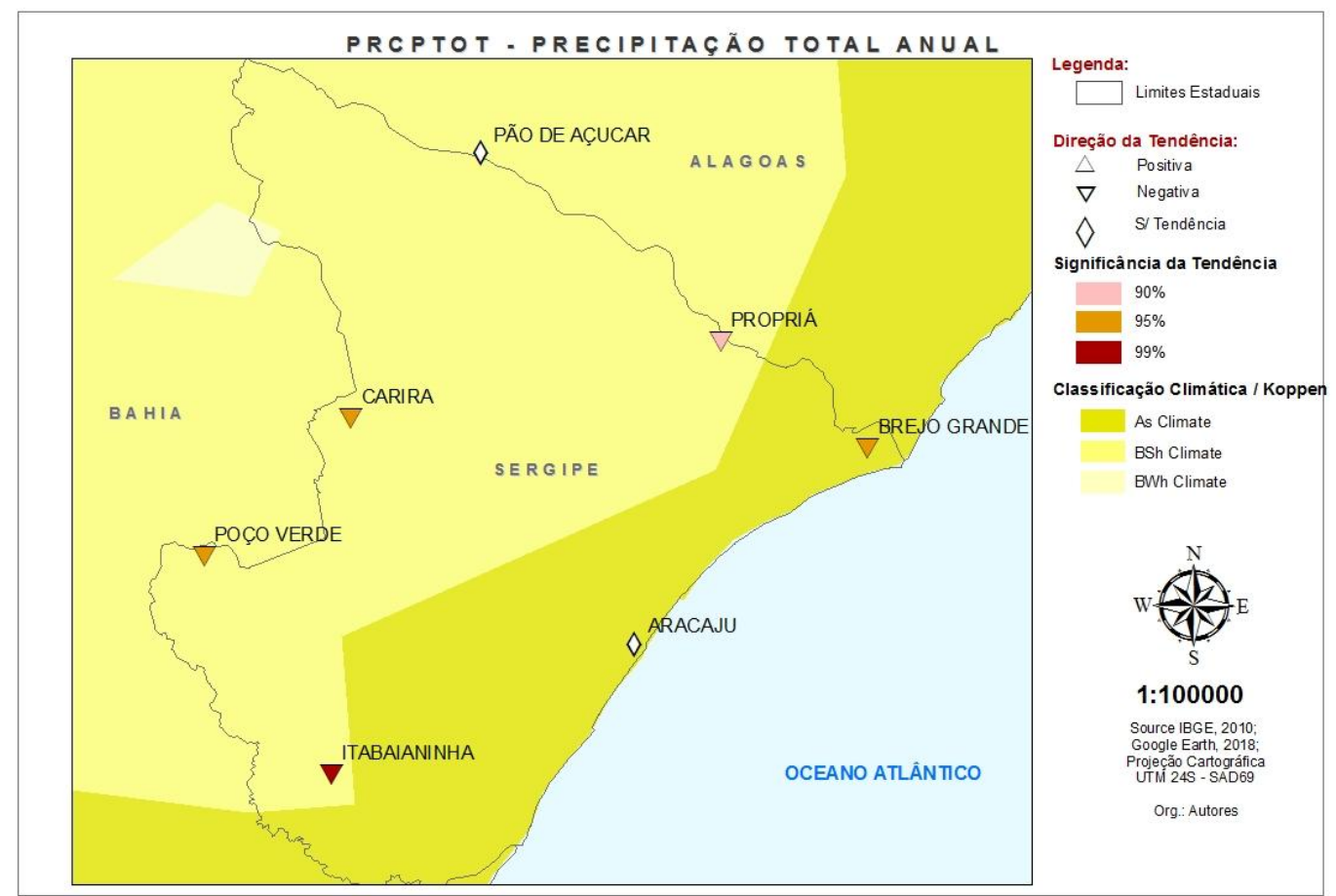

Figura 6: Tendências para o índice PRCPTOT. Fonte: IBGE e INMET, 2019. Org.: Autores

Os resultados trazem uma tendência negativa na maior das estações do estado sergipano. Foram encontradas tendências a queda nos valores anuais de chuva. Na estação de Itabaianinha, a tendência negativa teve significância de 99\%. Já nas estações Poço Verde, Brejo Grande e Carira, a significância foi de 95\%, enquanto que a de Propriá registrou 90\% de significância.

A estação na capital Aracaju, com uma série iniciada em 1961 não revelou tendências significativas para este índice.

Outro índice ligado às chuvas calculado para as cidades sergipanas foi o RX1DAY, que nos indica o valor máximo de chuva registrada em um único dia por mês e revelado pela Figura 7.

Para este índice, novamente, a maior parte dos municípios apresentou tendências negativas. Foi o caso de Aracaju e Propriá (99\% de significância), Carira e Brejo Grande (95\% de significância) e Poço Verde (90\% 
de significância), novamente Pão de Açúcar não registrou tendências significativas para este índice, juntamente a Itabaianinha.

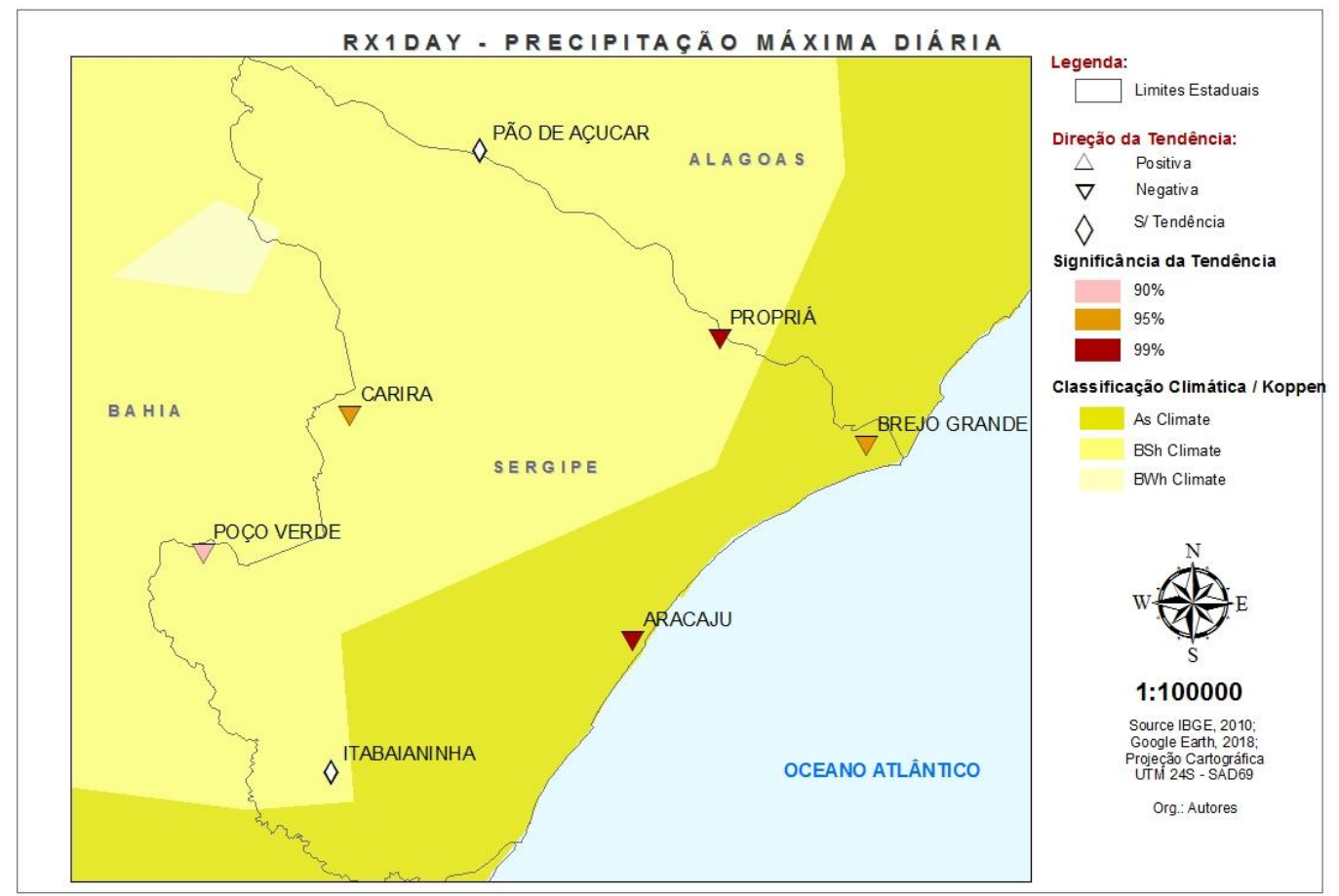

Figura 7: Tendências para o índice RX1DAY. Fonte: IBGE e INMET, 2019. Org.: Autores

O índice SDII calcula a intensidade das chuvas nas series temporais analisadas, dividindo o total de chuvas pelos dias em foram registradas precipitações. Seus resultados para o estado de Sergipe são apontados pela Figura 8.

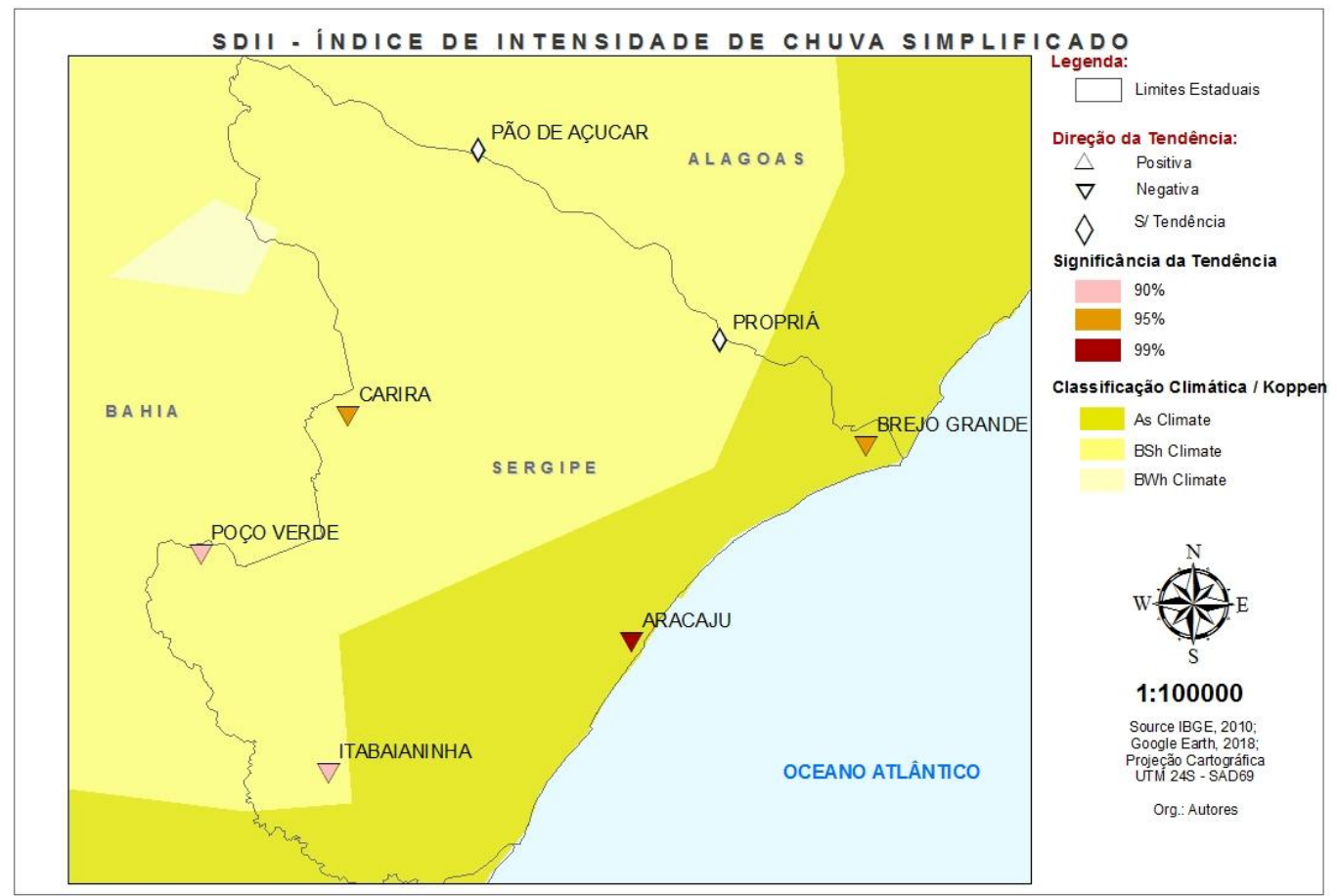

Figura 8: Tendências para o índice SDII. Fonte: IBGE e INMET, 2019. Org.: Autores

Resultados apontam tendência a diminuição na intensidade das precipitações em todos os pontos do estado, a exceção das cidades de Pão de Açúcar e Propriá. Nas demais, a tendência negativa mostrou-se com 99\% de significância em Aracaju, 95\% em Brejo Grande e Carira e 90\% em Poço Verde e Itabaianinha. Tais resultados complementam os vistos até aqui, que apontam tendências a diminuição nos valores de chuva e no tempo de duração de ditos eventos. 
Os dias contínuos com chuva, expressos pelo índice CWD, estão espacializados na Figura 9.

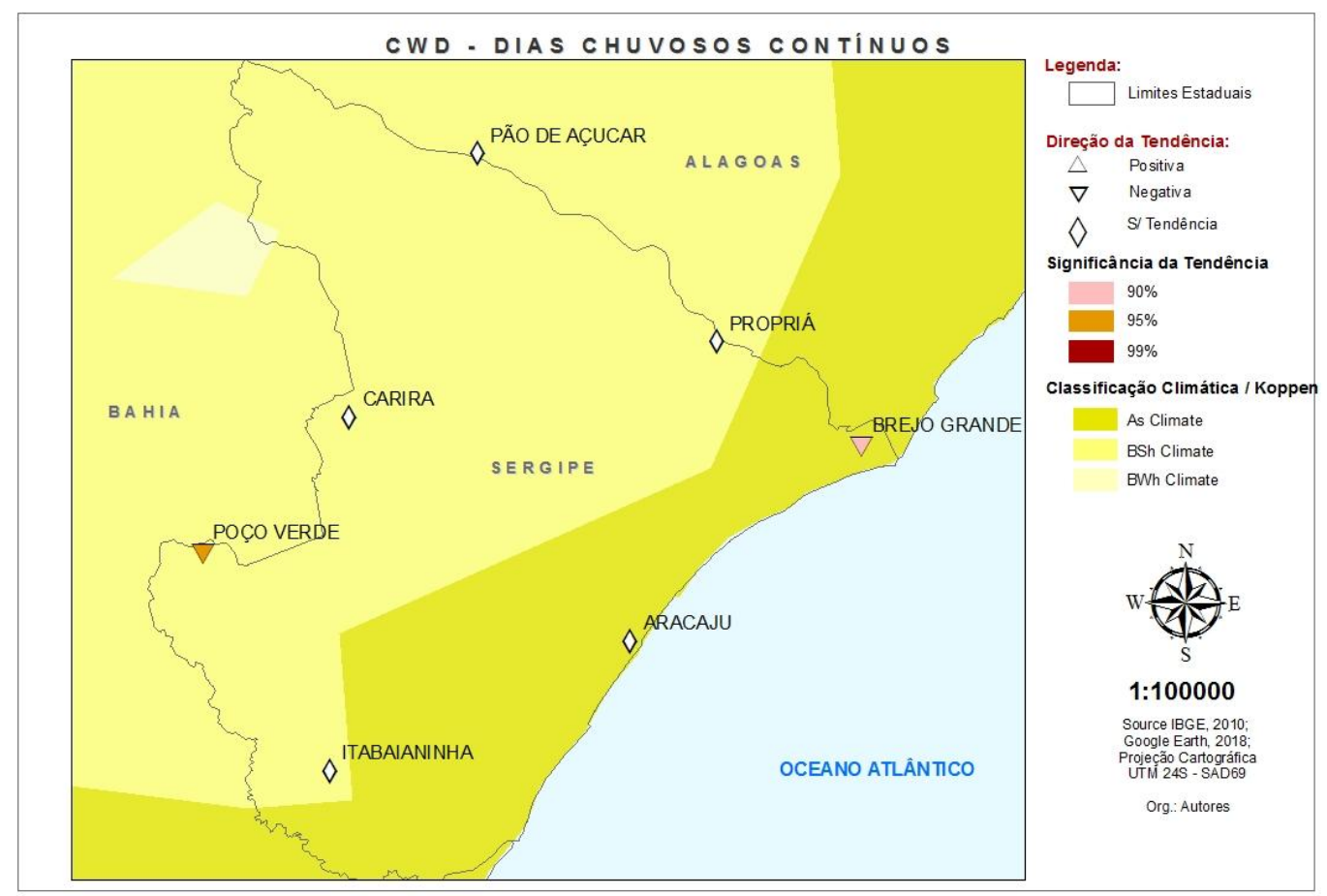

Figura 9: Tendências para o índice CWD. Fonte: IBGE e INMET, 2019. Org.: Autores.

Pode-se observar um predomínio dentre as cidades sergipanas, na ausência de tendências significativas, com exceção as cidades de Poço Verde, com tendência negativa a 95\% significância, e Brejo Grande, que registrou igualmente tendência negativa, mas com significância de $90 \%$.

Assim, percebe-se que, apesar da queda nos valores de chuva, a intermitência dos períodos chuvosos e secos não apresentou fortes modificações no estado, algo também atestado pela Figura 10 onde se retrata as tendências ao índice de dias contínuos secos.

As tendências ao índice de dias contínuos sem registros de chuva seguem linha semelhante, sendo registradas tendências positivas a tal índice apenas nas cidades de Propriá e Brejo Grande, ambas com 95\% de significância.

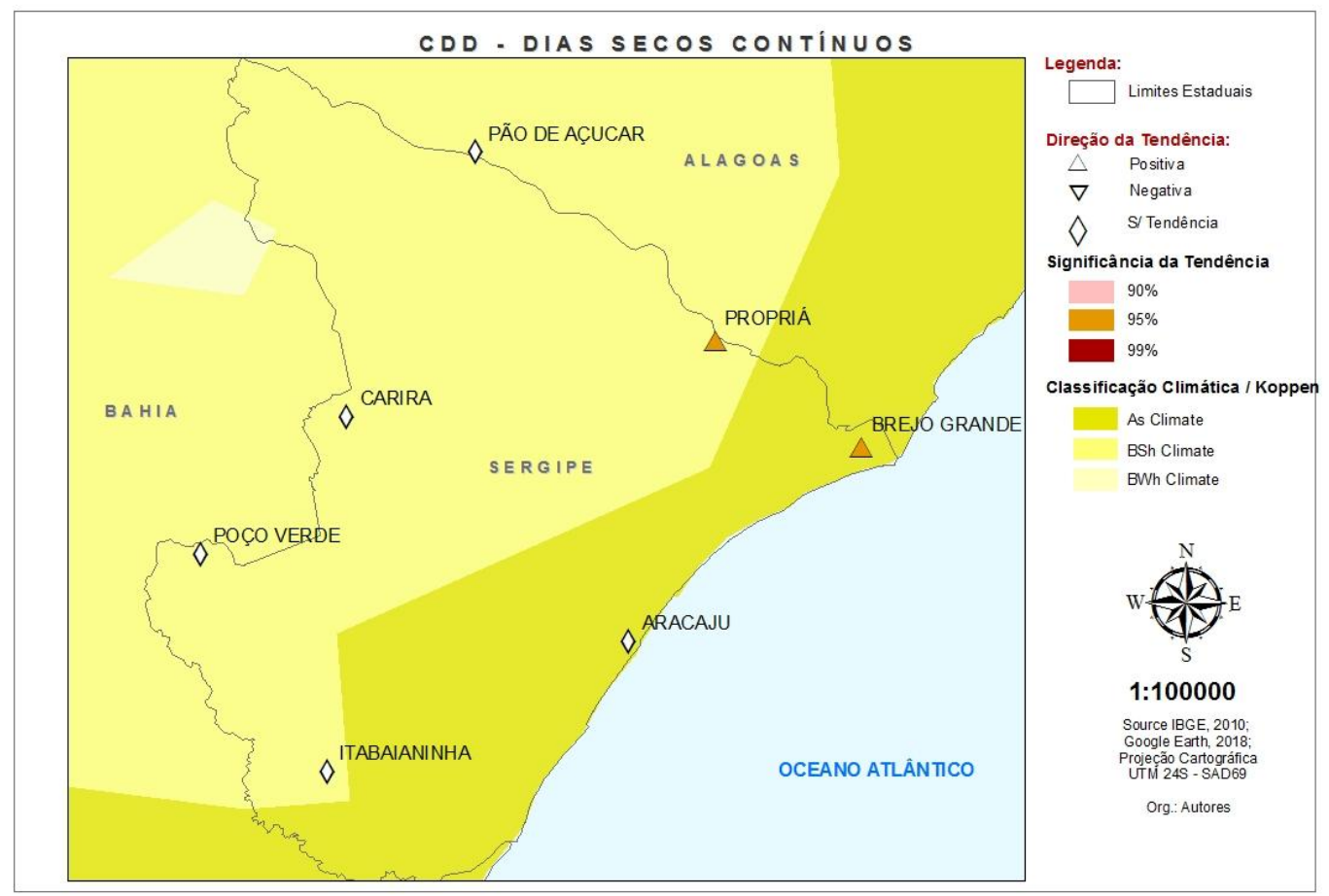

Figura 10: Tendências para o índice CDD. Fonte: IBGE e INMET, 2019. Org.: Autores 


\section{Discussão}

A espacialização das tendências para os índices climáticos extremos permite-nos analisar e prospectar como o clima do estado sergipano tem se portado.

Em relação às variáveis térmicas, observou-se uma ampla tendência, ao longo de todo estado, para aumento nos extremos tanto nas temperaturas máximas quanto mínimas.

As exceções ficaram as estações com menores series temporais, o que pode nos indicar que as alterações detectadas pelas tendências não sejam recentes e que tais estações, já tiveram suas séries iniciadas dentro da conjuntura das alterações climáticas observadas pelo Estado. Em cidades grandes, e que apresentaram crescimento urbano recente, como no caso da capital Aracaju, estas alterações podem inclusive ser consequência do crescimento urbano,visto que a população da cidade aumentou em quase seis vezes durante o período de análise e que tal processo, traz em seu lastro um notado aumento térmico.

Todavia, nas demais cidades onde o processo de aquecimento foi notado (Pão de Açúcar, Propriá, Itabaianinha e Poço Verde), todas na região do semiárido, o fenômeno urbano é menos intenso portanto, tal fato não pode ser considerado na justificativa do crescimento nas temperaturas. Assim, os resultados sugerem que o predominio das tendências positivas para as variáveis térmicas encontradas no Estado sergipano seria portanto fruto do processo de mudanças climáticas globais atuando na escala local.

Ditas cidades já tem nas suas elevadas temperaturas uma característica de suas paisagens e inclusive em sua cultura, fato este que tende a se acentuar.

No caso dos índices ligados a precipitação, nota-se fortemente as tendências à diminuição no volume e intensidade das chuvas ao longo de todo o território, tendências estas, observadas inclusive nas cidades cujas estações apresentam menores séries temporais.

Aumento na sequência de dias secos foi detectado nas cidades de Brejo Grande e Propriá, indicando que, na porção norte do estado, a tendência é que, não apenas a chuva torne-se mais escassa, como também o período de dias secos será maior.

Ditos cenários desenhados para as tendências pluviométricas apontam um estado com aridez cada vez mais intensa, situação inclusive já levantada por Dubreuil et al. (2018). Para cidades como Propriá, que apresentam chuvas anuais abaixo de $1.000 \mathrm{~mm}$, tal fato pode ser ainda mais intenso.

Em pesquisa analisando dados de estações meteorologicas para todo o nordeste, entre o período de 1961 e 2014, Costa et al. (2020a) encontraram resultados semelhantes, com tendencias significativas para o aumento de temperatura, e diminuição de totais de precipitaçao. Os autores utilizaram em seus estudos apenas três estações no estado sergipano, mas as constatações assemelham-se aos encontrados neste estudo.

Os cenários desenhados a partir das tendências climáticas obtidas não podem ser analisados de forma isolada, uma vez que compõe um quadro mais amplo da geografia sergipana. Há uma dinâmica socioambiental integrada.

A dinâmica geográfica do estado de Sergipe tem na cidade de Aracaju e seu entorno, seu principal ponto de concentração populacional, industrial, econômica e de serviços. Os cenários para a região litorânea apontam para o aumento de temperaturas, atrelada a reduções no volume de chuva. Embora os impactos aqui não sejam tão intensos se relacionados à região do semiárido, e tendo em vista o maior desenvolvimento social da região, há de se levar em conta ainda, a heterogeneidade de grupos sociais que compõe o tecido urbano em questão e que sofrerão de maneira igualmente heterogênea, com tais impactos.

A pesca e captura do caranguejo, por exemplo, situada como uma atividade tradicional ligada a comunidades ribeirinhas e quilombolas das grandes regiões estuarinas do estado sergipano, como no município de Brejo Grande (ALVES et al, 2017), estão entre as atividades que potencialmente serão afetadas pelos cenários propostos, em decorrência do aumento nas temperaturas das águas (BARROS; ALBERNAZ, 2014).

Segundo Alves et al. (2017) e Duarte e Rezende (2019), tais atividades, além de fornecer o recurso econômico necessário para comunidades inteiras do litoral sergipano, são partes da cultura e identidade tradicional local.

Analisando a migração interna no estado do Sergipe, a partir dos territórios de planejamento estaduais, Meneses e Santos (2014) atestam um emigração histórica dos territórios sertanejos com destino as regiões litorâneas do estado, com ênfase na grande Aracaju e região leste. A complexidade socioambiental da região do semiárido é tida como principal motivador para estes movimentos, que acabam por trazer consequências também para a capital e suas adjacências. 
O sertão sergipano é a região do estado que mais aglomera estabelecimentos rurais. Ditas atividades econômicas terão suas atividades diretamente afetadas pelas mudanças aqui apresentadas, uma vez que, os cenários desenhados sugerem uma escassez de água ainda mais profunda.

Dados do último censo agropecuário (IBGE, 2017) apontam que cerca de 10,2\% da população estadual (234 mil pessoas) estão ocupadas nestes estabelecimentos, os quais, cerca de $78 \%$ dos proprietários identificam-se como dentro de uma dinâmica de produção familiar e cerca de 82,5\% tem escolaridade até primeiro grau completo, deflagrando alto grau de vulnerabilidade social.

O resultado desta realidade para a migração estadual interna reflete a já citada, forte desigualdade social no estado. Segundo Meneses e Santos (2014) entre os anos de 2005 e 2010, as regiões do baixo São Francisco e Médio Sertão, foram as com menor taxa liquida de migração, com $-29,9 \%$ e $-19,7 \%$ respectivamente. Já a região da Grande Aracaju e do Leste sergipano, região imediatamente próxima a capital, foram as com maiores taxas, com 9,7\% e 20,2\% respectivamente.

A prospecção de cenários climáticos mais intensos no semiárido sergipano pode trazer como consequência um agravo a ditos movimentos já acentuados, que por sua vez, podem aumentar a pressão demográfica na porção costeira do estado.

Problemas socioambientais urbanos como poluição do ar e conforto térmico (ANJOS, 2017), poluição da água (SILVA; PINTO, 2013), questões de moradia (ARAÚJO, 2003) e abastecimento além da supressão de práticas tradicionais como a já citada captura do caranguejo e pesca artesanal e também atividades extrativistas ligadas a restinga, como a coleta da mangaba (JESUS; SANTOS, 2019) já são presentes na realidade aracajuana e concebidos como fruto de um processo de crescimento urbano intenso e sem planejamento, mas podem ser ainda mais acentuados com maiores fluxos migratórios oriundos do interior do estado.

\section{Considerações finais}

O estudo das tendências em índices climáticos permite-nos avaliar como e com que intensidade o clima do Sergipe tem se modificado. Para tanto foram utilizadas séries históricas de diferentes estações meteorológicas do estado.

Conforme citado, as séries apresentam tamanhos diferentes, de modo que em três delas, as séries apresentam apenas doze anos de dados. Optou-se por realizar a análise, mesmo com séries de tamanhos menores, para garantir maior representatividade espacial na análise. Sabe-se que o tamanho da série influi nos resultados dos cálculos de tendência, mas a exclusão de ditas estações ocasionaria em um estudo limitado a apenas três estações meteorológicas.

Observando os resultados, tem-se a ver que apontaram fortes tendências a aumento na temperatura e diminuição nas chuvas em todo estado. Admite-se que as alterações climáticas recentes observadas no estado sergipano possam ser consideradas frutos dos processos de mudanças climáticas globais.

Sob o ponto de vista geográfico, diversas podem ser as repercussões das alterações analisadas para o estado. Procuramos analisar questões econômicas, sociais, demográficas dentre uma ampla gama de consequências, mas é certo que a região do sertão será mais afetada pois já se trata da região do estado com o clima mais extremo.

A relação do sertanejo com o clima semiárido local perpassa aspectos físicos e fisiológicos, marcando profundamente seus aspectos culturais e identitários, não se limitando ao território sergipano e sendo eternizado em relatos clássicos como "Os Sertões" de Euclides da Cunha e "Geografia da Fome" de Josué de Castro, dentre tantos outros e as tendências aqui apresentadas fazem-nos reforçar a característica do sertanejo, apresentada por Euclides da Cunha como "antes de tudo, um forte".

\section{Agradecimentos}

Os autores agradecem a CAPES pelo financiamento desta pesquisa. 
Referencial bibliográfico

ANJOS, M.W.B. Orientações climáticas para o planejamento urbano numa cidade costeira do nordeste do Brasil: Aracaju-SE,Tese de Doutorado, Universidade de Lisboa, 2017.

ARAÚJO, H.M., Impactos Ambientais Urbanos Decorrentes Da Apropriação Do Relevo Em Aracaju, In: CONGRESSO DA ASSOCIAÇÃO BRSILEIRA DE ESTUDOS DO QUARTENÁRIO, 2003, Recife, Anais do IX Congresso da Associação Brasileira de Estudos do Quaternário, 2003. v. . p. 296-

ARAÚJO, W.S.; BRITO, J.I.B. Indices Of Trends Of Climatic Changes For The States Of The Bahia And Sergipe By Means Of Daily Precipitacion Indices And Its Relation With Sst's Of The Pacific And Atlantic, Revista Brasileira de Meteorologia, v.26, n.4, p. 541-554, 2011.

ALVES, N.M.S.; SILVA, D.B.; CARVALHO, I.S.M.; SANTANA, B.L.P.; ANDRADE, R.S. Mudanças No Cotidiano Das Comunidades Tradicionais Pesqueiras De Brejo Grande - Sergipe, Brasil, Revista GeoNordeste, n. 1, p. 187-202, 2017.

BARROS, D.F.; ALBERNAZ, A.L.M. Possible impacts of climate change on wetlands and its biota in the Brazilian Amazon, Brazilian Journal of Biology, v.74, n.4, p.810-820, 2014.

COSTA, R.L.; BAPTISTA, G.M.M.; GOMES, H.B.; SILVA, F.D.S.; ROCHA JÚNIOR, R.L.; SALVADOR, M.A.; HERDIES, D.L. Analysis of climate extremes indices over northeast Brazil from 1961 to 2014, Weather and Climate Extremes, v. 28, p.1-21, 2020a

COSTA, R.L.; GOMES, H.B.; SILVA, F.D.S.; ROCHA JÚNIOR, R.L.; SILVA, G.C.S.; ROMÃO, W.M.O. Tendências em índices extremos de precipitação em Cabaceiras (PB) para períodos distintos, Revista Brasileira de Geografia Física, v.13, n.01, p.271-285, 2020

DUARTE, T.L.S.; REZENDE, V.A. Degradação dos manguezais em Aracaju/SE (Brasil): impactos socioeconômicos na atividade de catador do caranguejo-uçá (Ucides cordatus), Revista Brasileira de Meio Ambiente, v.7, n.1, p.86-97, 2019.

DUBREUIL, V; FANTE, K.P; PLANCHON, O.; SANT'ANNA NETO, J.L. Climate change evidence in brazil from Koppen's climate annual types frequency. International Journal Of Climatology, v. 1, p. 1-14, 2018.

IBGE, Censo Demográfico 2010, 2010, Disponível em: <http://www.censo2010.ibge.gov.br>.

IBGE, Pesquisa Nacional por Amostra de Domicílios, 2019, Disponível em: <https://www.ibge.gov.br/estatisticas/sociais/trabalho/9171-pesquisa-nacional-por-amostra-de-domicilioscontinua-mensal.html?=\&t=0-que-e>

IBGE, Censo Agropecuário, 2017, Disponível em: <https://censos.ibge.gov.br/agro/2017/>.

IPCC, Climate Change 2014: Impacts, Adaptation, and Vulnerability. Part A: Global and Sectoral Aspects. Contribution of Working Group II to the Fifth Assessment Report of the Intergovernmental Panel on Climate Change, Field, C.B.; Barros, V.R.; Dokken, D.J.; Mach K.J.; Mastrandrea, M.D.; Bilir, T.E.; Chatterjee, M.; Ebi, K.L.; Estrada, Y.O.; Genova, R.C.; Girma, B.; Kissel, E.S.; Levy, A.N.; MacCracken S.; Mastrandrea, P.R.; White L. L. (eds.). Cambridge University Press, Cambridge, United Kingdom and New York, NY, USA, 1132, 2014.

JESUS, P.S.; SANTOS, H.J.S. O Movimento Das Catadoras De Mangaba De Sergipe: Entre Finalidades E Avanços, Revista GeoNordeste,n. 1, p. 91-109, 2018.

KEGGENHOFF, I.; ELIZBARASHVILI, M.; AMIRI-FARAHANI, A.; KING, L. Trends in daily temperature and precipitation extremes over Georgia, 1971-2010, Weather and Climate Extremes, V.4, p. 75-85, 2014.

KENDALL, M. G. Rank correlation methods. $4^{\mathrm{a}}$ ed., London: Charles Griffin, 1975. 
MANN, H. B. Nonparametric tests against trend. Econometrica, vol. 13, n. 3, p. 245259 p. The Econometric Society, 1945.

MARENGO, J. O futuro clima do Brasil. Revista USP, v.103, 25-32, 2014.

MENESES, N.S.; SANTOS, J.A.M. Aspectos da Migração em Sergipe, In: VIII COLÓQUIO

INTERNACIONAL DE EDUCAÇÃO E CONTEMPORANEIDADE, 2014, São Cristovão, Anais..., São Cristovão, UFS, 2014, p. 291-

MOREIRA, J.G.V.; NAGHETTINI,M., Detecting Monotonous Time Trends as Related to Type I and Type II Errors: Case Study in Annual Maximum Daily Precipitation Series Observed in the State of Acre, Revista Brasileira de Meteorologia, v.31, n.4, p.394-402, 2016

NATIVIDADE,U.A.; GARCIA, S.R.; TORRES, R.R. Tendência dos Índices de Extremos Climáticos Observados e Projetados no Estado de Minas Gerais, Revista Brasileira de Meteorologia, v.32, n.4, p.600614,2017

OLIVEIRA, A.S.; MELLO, C.R.; MARQUES, R.F.P.V. Temporal Trends Of Climate Indices Associated With Precipitation And Air Temperature In Minas Gerais, Brazil, Revista Brasileira de Climatologia, v. 26, p. 499-520, 2020.

PENEREIRO, J.C.; MARTINS, L.LS.; BERETTA, V.Z. Identificação De Variabilidadese Tendências Interanuais Em Medidas Hidro-Climáticas Na Região Hidrográfica Do Tocantins-Araguaia, Brasil, Revista Brasileira de Climatologia Geográfica, v.18, p. 219-241, 2016.

PETERSON,T.C.; FOLLAND,C.; GRUZA,G.; HOGG,W.; MOKSSIT, A.PLUMMER, N. Report on the Activities of the Working Group on Climate Change Detection and Related Rapporteurs, ETCCDI, 2001.

PINHEIRO, G. M. Variabilidade Temporo-Espacial da Pluviosidade da Bacia do Alto Iguaçu, Tese de Doutorado - UFPR, Curitiba, p.180, 2016.

PINTO, J. E. DE S. Análise têmporo-espacial da pluviosidade do Estado de Sergipe, Dissertação de Mestrado - USP, 1985.

PINTO, J. E. DE S. Os reflexos da seca no Estado de Sergipe. São Cristóvão: Editora do NPGEO/UFS, 1999.

PINTO, J. E. DE S.; SOUZA, I.F.DE; FACCIOLI,G.G.; SILVA, V.P. R.. A geografia das chuvas no baixo São Francisco sergipano: Configuração e perspectiva. In: AGUIAR NETTO, A.O. \& SANTANA, N. R.F.(Orgs.) Contexto socioambiental das águas do rio São Francisco. São Cristóvão: Editora UFS, 2015. P 69-90.

RAZAVI, T.; SWITZMAN, H.; ARAIN,A; COULIBALY, P. Regional climate change trends and uncertainty analysis using extreme indices: A case study of Hamilton, Canada, Climate Risk Management, v.13, p. 43-63, 2016.

SANCHES, F.O.; MAY, G.C.; SILVA, R.V.; FERREIRA, R.V. Chuvas No Norte Gaúcho: Um Estudo Sobre Atendência Das Chuvas E Mudanças Climáticas, Revista Brasileira de Climatologia, v.18, p.349$360,2019$.

SILVA, D.A.; PINTO, J.E.S.S., Águas Urbanas e Produção do Espaço em Aracaju/SE, Revista Geonordeste, Edição Especial "30 Anos de contribuição à Geografia", 2013.

SUDENE, Nova Delimitação Semiárido, 2018, Disponível em: <http://antigo.sudene.gov.br/images/arquivos/semiarido/arquivos/Rela\%C3\%A7\%C3\%A3o_de_Munic\%C3 \%ADpios_Semi\%C3\%A1rido.pdf $>$. 
(1) (2) (2)

Este artigo é distribuído nos termos e condições do Creative Commons Attributions/Atribuição- 